\title{
Primary health care nursing students' knowledge of and attitude towards the provision of preconception care in KwaZulu-Natal
}

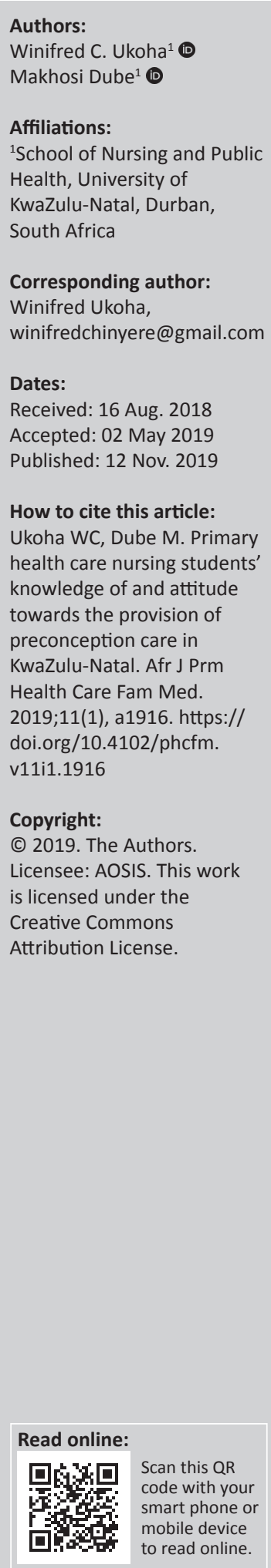

Background: Sub-Saharan African countries have been the worst affected by the high incidence of maternal and child mortality rates and HIV/AIDS (human immunodeficiency virus/acquired immunodeficiency syndrome) pandemic. Preventive care is the area that requires serious attention as a lot of maternal and child morbidity and mortality can be averted through rendering comprehensive care to women of child-bearing age. Preconception care (PCC) is recognised as an important factor in improving pregnancy outcome; yet, most primary health care (PHC) nurses lack the necessary resources to render PCC.

Aim: To describe the PHC nursing student's knowledge of and attitude towards the provision of PCC.

Setting: Higher Education Institution that offers PHC programme at six different sites to nurses working in the PHC clinics in the province.

Methods: A quantitative, non-experimental, descriptive study design was used. The total population from three sites selected, based on their geographical location were all invited to participate in the study. Questionnaire was used to collect data which was subsequently analysed using the Statistical Package for Social Sciences (SPSS) version 24.

Results: The response rate was approximately $85 \%(n=138)$. The respondents have practised in the PHC clinic for more than 1 year. Study centre, age and area of employment were found to be predictors of knowledge, but no direct association was found between the demographic factor and attitude. Furthermore, a significant difference was found between knowledge and age, and between the area of employment and attitude.

Conclusion: PHC nursing students were knowledgeable and had a favourable attitude towards PCC, but the absence of PCC resources in many practices has hindered them to a greater extent. It is recommended that for proper implementation of PCC to occur, health care workers should be provided with the necessary resources.

Keywords: primary health care; nurses; preconception care; pre-pregnancy counselling; knowledge; attitude.

\section{Introduction}

Preconception care (PCC) or pre-pregnancy care according to World Health Organization ${ }^{1}$ is 'the provision of biomedical, behavioural and social health interventions for women and couples before conception occurs'. The aim of this care is to improve the health status of individuals by reducing behaviours and environmental elements that contribute to poor pregnancy outcomes. ${ }^{2}$ The World Health Organization (WHO) reports purported that intervening after conception has occurred is usually too late in reducing risk factors which might affect the mother and her unborn child. ${ }^{1}$

Sub-Saharan Africa has been identified to be the area worst affected by the high rate of maternal and child mortality and morbidity rates. ${ }^{3}$ According to the report published by the WHO in 2014, 289000 maternal deaths occurred globally in 2013; 99\% of them were from low and middleincome countries. Over two-thirds (60\%) of all these maternal deaths occurred in sub-Saharan Africa. Still, the likelihood of a 15-year-old girl in sub-Saharan Africa dying due to complications related to childbirth is as high as 1:37, when compared to 1:3400 in developed countries. On the other hand, it was projected that in sub-Saharan Africa, 1:12 children die before reaching the age of five, as compared to 1:147 seen in the developed countries. ${ }^{3}$ 
The South Africa's 2010-2013 'National Committee on Confidential Enquiries into Maternal Deaths' ${ }^{4}$ reports recognised non-pregnancy related infections, obstetric haemorrhage and complications of hypertension in pregnancy as the three conditions that contribute mainly to the preventable maternal deaths. The above-named conditions contribute to $66.7 \%$ and $56.8 \%$ of the possible and probable avoidable maternal deaths in South Africa and KwaZulu-Natal (KZN), respectively. ${ }^{4}$

Even though many initiatives have been undertaken both globally and nationally to address this issue, the majority of them are not tackling the problem at the grassroots level, which is preconceptionally. Preventive care in health is the area that requires serious attention as a lot of maternal and child morbidity, and mortality can be averted through rendering comprehensive holistic care to reproductive-aged women..$^{5}$ Recently, there has been a call on governments to decrease the amendable risk factors for non-communicable diseases and the core social determinants of diseases by 2020.5

To reach the sustainable development goal (SDG) $3,{ }^{6}$ especially target 3.1 and 3.2 which aims by 2030 to 'reduce the global maternal mortality ratio to less than 70 per 100000 live births and to end preventable deaths of new-borns and children under five' respectively, much greater effort is needed from all the stakeholders. This effort is especially needed towards the preventive aspect; hence United Nations Children's Fund (UNICEF) has encouraged an acceleration of the pace of progress that targets child survival, especially in high mortality areas in sub-Saharan Africa. ${ }^{7}$

\section{Background}

Preconception care has been advocated as a major intervention to decrease maternal and child mortality. ${ }^{8}$ It is noteworthy that PCC aims to optimise maternal and child health, which is of great importance to adolescents and men and not just prospective parents. Studies have shown the significance of preconception care and the existing interventions. ${ }^{9,10,11}$ PCC has been proven to help prevent pre-term deliveries for all women; inhibit pregnancy in adolescent years and unintended pregnancy; optimise pre-pregnancy weight; promote healthy nutrition which includes the intake of supplements; screening, identifying and handling mental health; and intimate partner violence. It also promotes the vaccination of children and adolescents, prevents and treats sexually transmitted infections including HIV / AIDS (human immunodeficiency virus/acquired immunodeficiency syndrome) screening; diagnoses and manages chronic disease; promotes ending of tobacco use and restricts contact to second-hand smoke. ${ }^{9}$ The problem of obesity is very pronounced in South Africa. Both obesities of mothers and fathers have been recognised to effect the health of the child and contribute to other risk factors in the mothers. ${ }^{12}$ Prepregnancy excess weight increases the risk of hypertensive disorders of pregnancy, preeclampsia and gestational diabetes. ${ }^{13}$ Preconception care services are suggested by different stakeholders and studies as a valuable tool to meet the 909090 global target by ensuring that those who are negative remain negative and those who are positive have their viral load suppressed, before conception occurs, so as to decrease the likelihood of infecting the unborn child..$^{14,15,16}$ Teenage pregnancy and child-bearing are among the biggest contributing factors to high maternal and child morbidity and mortality rates around the world. ${ }^{17}$ Teenage pregnancy is a problem in the South African society, and the rendering of preconception services to all women of reproductive age has been reported as a means of reducing the incidences of both teenage and other unplanned pregnancies. ${ }^{18}$ Globally, complications due to pregnancy are the primary cause of death among women between the ages of 15-19 years. Therefore, interventions to delay pregnancy among this group will subsequently reduce the maternal mortality rate. Studies conducted in the United States reveal that strategies that promote preconception health among this group are needed. ${ }^{17}$ It was found that preconception care should start in adolescent years and continue as inter-conception care to give chances for positive behavioural modifications to happen before pregnancy can occur. ${ }^{10}$

\section{Problem statement}

Preconception care is not well-implemented in South Africa and many other countries worldwide; ${ }^{19}$ despite the agreement that to improve pregnancy outcome, a continuum of care should be delivered from pregnancy, delivery, the postnatal period, infancy and childhood, adolescence and on to adulthood. ${ }^{20}$

The knowledge of health professionals and women about preconception is low globally, and there is a confusion among health workers about who is responsible for the provision of PCC. ${ }^{21}$ The knowledge of the content of PCC guidelines is also a problem among primary health care workers as a Brazilian study reveals an awareness of the presence of a protocol but uncertainty with regard to its content. ${ }^{22}$ Moreover, studies have revealed that the primary health care providers' knowledge and implementation of PCC protocols toward safer conception among HIV-infected women are inadequate, ${ }^{23}$ resulting in high incidences of both horizontal and vertical transmission of HIV and underutilisation of services by women, as well as poor adherence. ${ }^{24}$ The number of new HIV infections is not reducing as they should be, as many women (about 3\%) are still seroconverting during pregnancy in South Africa. ${ }^{25}$ This high incidence of HIV seroconversion during pregnancy in South Africa has been mentioned to be the major cause of the failure of prevention of mother-to-child transmission of HIV. ${ }^{26}$ Notwithstanding the level of health education and counselling being given to women, there is still an increased level of unplanned pregnancy among the general population and also among women living with HIV (33\% vs. 50\%), ${ }^{27}$ which is indicative of a lack of knowledge about PCC and lack of provision of PCC by health care workers. ${ }^{23}$

Although the primary health care (PHC) nurses are at the forefront of rendering preventive interventions, both in the primary health care and in the community settings, PCC is 
not always provided to women in the PHC setting and women find that health professionals scarcely discuss the availability and need for PCC with them. ${ }^{28}$ There is, however, the paucity of studies that specifically examined PHC nurse's knowledge and attitudes regarding PCC, ${ }^{29,30}$ especially in developing countries, which is the focus of this study. Additionally, much literature on the topic of discussion exists only in developed countries, and the few studies that are found in the African context are not very specific, but PCC is rather incorporated into other services. ${ }^{8,31}$ Hence there is scarce literature regarding PCC and counselling in the context of Africa. Moreover, many studies on PCC around the world did not target primary health care nurses in isolation, therefore, they were studied together with other primary health care workers. Therefore, investigation of the knowledge and attitudes of PHC nurses is very necessary.

\section{Research methodology Research design}

A non-experimental, descriptive, and cross-sectional survey was employed for this study. Through quantitative descriptive studies, a researcher discovers new meaning, describes what is known, determines the frequency with which something occurs, and categorises the information using a predetermined instrument. ${ }^{32}$ This method gives a broader explanation of the knowledge and attitude of PHC nursing student towards the provision of PCC.

\section{Setting}

The research setting for this study was a higher education institution (HEI) in KZN. This study targeted a programme that uses a decentralised mode of teaching in PHC. This primary health care programme is offered at six different sites around KZN to nurses who are already working in the PHC clinics in the province. For this study, three sites under the patronage of the selected HEI were considered, namely Durban, Pietermaritzburg, and Empangeni. These three settings were selected based on their geographical location and characteristics (urban, semi-urban and rural), and accessibility.

\section{Study population and sampling strategy}

The three selected sites have a population of 163 PHC nursing students. Convenience sampling method was used to enrol PHC nursing student from the selected sites who met the criteria, who had agreed to participate in the study. All the PHC nursing students available from the selected sites were asked to participate in the study but 138 out of 163 participated in the study. The minimum sample size required in a population of 200, to achieve a 95\% level of confidence and 5\% margin of error according to Leslie Kish was $134 .^{33}$ Therefore, a sample size of 138 for a population of 163 is considered very adequate for this study.

The inclusion criterion considers all nurses enrolled in the PHC programme and registered with South African
Nursing Council (SANC) as general, community and midwifery nurses, and were willing to participate in the study. All those who had de-registered or were on long sick leave or those that did not practice in a primary health care setting or did not render services to women in the reproductive age and those other under the age of 18 were excluded from the study.

\section{Research Instrument and validity}

The self-administered questionnaire was used to collect data. The instrument was adapted from studies on PCC conducted in the United Kingdom and the Netherlands. ${ }^{29,30}$ It consisted of three sections A to C. Section A was the demographic data, B was composed of the two knowledge parts and $C$ was the attitude. The two instruments were merged to form the knowledge and the attitude section of the instrument, while the researcher added the demographic section. The content and face validity of the instrument were assessed through extensive literature review and in line with the study objective and with the help of the supervisor. The study instrument was pretested by means of a test-retest method to measure the stability and reliability of the instrument over time. The test-retest involved five PHC facilitators who also work in the PHC setting and they were not included in the main study. The 'Cronbach's alphas' for the various sections of the questionnaire were as follows: knowledge: 0.85 and attitude: 0.70 .

\section{Data collection procedure}

The study data were collected in October 2017 at the three centres. Consent form, together with information sheet with details of the study, was given to the participants to obtain an informed consent. Questionnaires were subsequently handed out to those who consented to the study, and they were guided on how to complete it. The completed questionnaires were returned at the participant's convenience.

\section{Data analysis}

Responses from the questions were coded numerically by assigning numbers to the responses given by the respondents to enable analysis of data. 'Statistical Package for Social Sciences' (SPSS) version 24 was used to capture and analyse the collected data. The knowledge of PCC as a whole was measured using 10 items on five-point Likert scale, which ranged from strongly disagree to strongly agree. The attitude of PCC was also assessed using 12 items on a five-point Likert scale. The strongly disagree was scored as one and strongly agree scored as five in a positive statement whereas the score was reversed in negative statements. The knowledge and attitude score were further computed to come up with a composite score where respondents who scored below the 75th percentile were categorised as not knowledgeable or with unfavourable attitude while those who scored above the 75th percentile were categorised as knowledgeable or with a favourable attitude. Descriptive statistics, mainly percentages and frequencies, were used to describe and synthesise data, while frequency tables were used to display the frequency 
of data. The 'Kruskal-Wallis test', 'Mann-Whitney U test', 'Fishers exact test' and 'Pearson chi-squared test' was used to test if the distribution of knowledge and attitude differed across the nurses' social demographic characteristics. A Chi-square test was used to ascertain the independence of knowledge and attitude of nurses towards PCC. As some of the chi-squared test was significant, 'Logistic Regression' was further used to identify factors influencing knowledge level. The level of significance was set at 0.05. Furthermore, the crude odd ratios (COR) and adjusted odds ratios (AOR), respectively, were used to explain the relationship between knowledge and the demographic profile of the study population.

Results from the univariate logistic regression model (crude odds ratio) informed the profile of variables to be included into the multivariate logistic regression model. The analysis was all made fixing the confidence interval (CI) at $95 \%$

\section{Ethical considerations}

Ethical clearance for the study was obtained from the University of KwaZulu-Natal (Ethical Committee protocol reference number HSS/0994/017M). This was done to protect the rights of the respondents. Gate keeper's permission was sought from the registrar and the dean of the HEI before conducting the study. The respondents gave their consent before the questionnaires were distributed to them, and all ethical considerations were maintained, especially anonymity and confidentiality.

\section{Results}

Out of 163, 138 questionnaires distributed were returned giving a response rate of approximately $85 \%$.

\section{Sociodemographic data}

In this study, of 138 PHC nurses, the majority (83.3\%) were female. Approximately 47\% were aged between 31 and 40 years, and only $8.7 \%$ were aged 51 years and above. They were mainly African (92.8\%) and 58.7\% were married.

For the years of experience, $80.4 \%$ had worked from 1 to 5 years, while $19.6 \%$ had worked for more than 6 years. The employment area was divided among $83.3 \%$ for the public clinic, $12.3 \%$ for the municipal clinic, and $4.3 \%$ for non-governmental organisation (NGO) and others. For the study centre of the respondents, $38.4 \%$ were from Durban, $29 \%$ were from Pietermaritzburg and $32.6 \%$ were from Empangeni.

\section{Knowledge of preconception care}

The findings of the respondent's knowledge of PCC showed that on a more favourable note, the majority of the respondents $88.4 \%(n=122)$ agreed that PCC can lead to better pregnancy outcome, while $92 \%(n=127)$ agreed, that PCC could reduce the incidences of unplanned and unwanted pregnancy.
Similarly, a further 92.8\% $(n=128)$ agreed that PCC could reduce maternal and child mortality rate and $89.9 \%(n=124)$ agreed PCC is for all women of child-bearing age. Most of the respondents $84.1 \%(n=116)$ agreed, that PCC could reduce the incidences of HIV PCR positive and more than two-thirds $71.8 \%(n=99)$ agreed that PCC could reduce the chances of acquiring HIV among serodiscordant couples while $42.8 \%$ agreed that there is little evidence base for PCC. On a less favourable note, more than two-thirds of the respondents $68.1 \%(n=94)$ disagreed that PCC would not change the patient's risk profile and a further majority $81.2 \%(n=112)$ disagreed that PCC should only be offered to women with high risks. On the other hand, $44.9 \%(n=62)$ were uncertain regarding the absence of PCC policy in South Africa, while $39.2 \%(n=54)$ had disagreed and $15.9 \%(n=22)$ agreed.

The knowledge about PCC had 10 items; thus, the possible minimum score was 10 , and the maximum score was 50 . The minimum score for the respondents was 28, and the maximum score was 50; $M=39.7$ and s.d. (standard deviation) $=4.8$. On grouping of the scores, with a score of less than 39 indicating not knowledgeable and 40-50 knowledgeable, the majority of respondents $55.0 \%(n=76)$ fell within the knowledgeable group while $45.0 \%(n=62)$ were in the not knowledgeable group. Hence, on average, the result indicated that the participants was knowledgeable about PCC.

\section{Predictors of good preconception care knowledge and favourable preconception care attitude}

The knowledge of PCC was compared with the demographic factors of the respondents to assess the predictor of good knowledge. As shown in Table 1, the knowledge of PCC was compared between the three study centres. Urban students' knowledge of PCC was compared with their counterparts in semi-urban and rural areas. The AOR for semi-urban was 2.6 (95\% CI 0.9-6.7), while for the rural population was 5.3 (95\% CI 1.9-14.5). Students from rural areas are 5.3 times more likely to be knowledgeable about PCC as compared to urban students. Also, students from semi-rural were 2.6 times more likely to be knowledgeable about preconception care as compared to urban students.

The knowledge level as compared across the age groups with ages $20-30$ as the reference group revealed that ages $31-40$ are $20 \%$ less likely to be knowledgeable about PCC and ages 41-50 were 1.5 times more likely to be knowledgeable while those above 50 years of age were $80 \%$ less likely to be knowledgeable about preconception care. The knowledge of the respondents was compared across their employment areas with those in the public clinic as the reference group showed that those in the municipal clinics are 7.3 times more likely to be knowledgeable and those working for the NGO's and others not mentioned are 50\% less likely to be knowledgeable. There was no significant association between gender, race, religion, marital status, years of experience and knowledge levels. 
TABLE 1: Logistic regression analysis showing the respondents knowledge towards preconception care.

\begin{tabular}{|c|c|c|c|c|c|c|c|c|c|c|}
\hline \multirow[t]{3}{*}{ Factor } & \multicolumn{4}{|c|}{ PHC Nursing Students' Knowledge of PCC } & \multirow[t]{3}{*}{$p$} & \multirow[t]{3}{*}{ COR } & \multirow[t]{3}{*}{$95 \% \mathrm{Cl}$} & \multirow[t]{3}{*}{$p$} & \multirow[t]{3}{*}{ AOR } & \multirow[t]{3}{*}{$95 \% \mathrm{Cl}$} \\
\hline & \multicolumn{2}{|c|}{ Knowledgeable } & \multicolumn{2}{|c|}{ Not knowledgeable } & & & & & & \\
\hline & $n$ & $\%$ & $n$ & $\%$ & & & & & & \\
\hline \multicolumn{11}{|l|}{ Study centre } \\
\hline Urban & 24 & 45.3 & 29 & 54.7 & 0.057 & 1 & - & 1 & 1 & - \\
\hline Semi-urban & 21 & 52.5 & 19 & 47.5 & 0.49 & 1.3 & $0.5-3.0$ & 0.05 & 2.6 & $0.9-6.7$ \\
\hline Rural & 31 & 68.9 & 14 & 31.1 & 0.02 & 2.7 & $1.1-6.1$ & 0.001 & 5.3 & $1.9-14.5$ \\
\hline \multicolumn{11}{|l|}{ Age } \\
\hline $20-30$ & 17 & 53.1 & 15 & 46.9 & 0.049 & 1 & - & 1 & 1 & \\
\hline $31-40$ & 35 & 53.8 & 30 & 46.2 & 0.9 & 1.0 & $0.4-2.4$ & 0.7 & 0.8 & $0.3-2.0$ \\
\hline $41-50$ & 21 & 72.4 & 8 & 27.6 & 0.12 & 2.3 & $0.7-6.7$ & 0.5 & 1.5 & $0.4-4.8$ \\
\hline $51+$ & 3 & 25.0 & 9 & 75.0 & 0.15 & 0.3 & $0.0-1.2$ & 0.05 & 0.2 & $0.04-1.0$ \\
\hline \multicolumn{11}{|c|}{ Employment area } \\
\hline Public clinic & 61 & 53.0 & 54 & 46.9 & 0.11 & 1 & - & 1 & 1 & - \\
\hline Municipal clinic & 13 & 76.5 & 4 & 23.5 & 0.08 & 2.9 & $0.8-9.3$ & 0.005 & 7.3 & $1.8-29.3$ \\
\hline \multicolumn{11}{|l|}{ Gender } \\
\hline Male & 12 & 52.2 & 11 & 47.8 & 0.821 & - & - & - & - & - \\
\hline Female & 64 & 55.7 & 51 & 44.3 & - & - & - & - & - & - \\
\hline \multicolumn{11}{|l|}{ Race } \\
\hline Black & 69 & 53.9 & 59 & 46.1 & 0.386 & - & - & - & - & - \\
\hline Indian & 4 & 57.1 & 3 & 42.9 & - & - & - & - & - & - \\
\hline Mixed race & 3 & 100.0 & 0 & 0.0 & - & - & - & - & - & - \\
\hline \multicolumn{11}{|l|}{ Religion } \\
\hline Christian & 68 & 54.8 & 56 & 45.2 & 1.000 & - & - & - & - & - \\
\hline Islam & 2 & 66.7 & 1 & 33.3 & - & - & - & - & - & - \\
\hline Hindu & 2 & 50.0 & 2 & 50.0 & - & - & - & - & - & - \\
\hline Traditional & 4 & 57.1 & 3 & 42.9 & - & - & - & - & - & - \\
\hline \multicolumn{11}{|l|}{ Marital status } \\
\hline Single & 45 & 55.6 & 36 & 44.4 & 0.971 & - & - & - & - & - \\
\hline Separated & 1 & 100.0 & 0 & 0.0 & - & - & - & - & - & - \\
\hline \multicolumn{11}{|c|}{ Years of experience } \\
\hline $1-5$ & 61 & 55.0 & 50 & 45.0 & 0.319 & - & - & - & - & - \\
\hline $6-10$ & 11 & 55.0 & 9 & 45.0 & - & - & - & - & - & - \\
\hline $11-20$ & 4 & 80.0 & 1 & 20.0 & - & - & - & - & - & - \\
\hline 21 and above & 0 & 0.0 & 2 & 100.0 & - & - & - & - & - & - \\
\hline
\end{tabular}

PHC, primary health care; PCC, preconception care; COR, crude odd ratios; AOR, adjusted odds ratios; Cl, confidence interval; NGO, non-governmental organisation.

\section{Attitude towards preconception care}

The results revealed that most respondents are on a less favourable note; $45.7 \%(n=63)$ disagreed that a dedicated clinic for PCC is a luxury service, while $49.2 \%(n=68)$ disagreed that a hospital setting was the best place to provide PCC, and interestingly, 58.7\% $(n=81)$ disagreed that there was not enough time to provide. In the same vein, $47.8 \%$ $(n=66)$ disagreed that as PHC nurses they did not have enough skills to offer PCC, and more than two-thirds of the respondents $82.6 \%(n=114)$ disagreed that $\mathrm{PHC}$ nurses were not the best people to offer PCC and more than two-thirds 69.6\% $(n=96)$ disagreed that initiating the talk about pregnancy wishes was uncomfortable. Similarly, 57.3\% ( $n=79)$ disagreed that PCC, without women asking for it, was objectionable. On the favourable note, the majority of the respondents $93.5 \%(n=129)$ agreed that PCC is an important health issue for women of child-bearing age and $47.1 \%$ $(n=65)$ agreed that in their practice, population planning for pregnancy does not often happen. The results further showed that more than half of the respondents $52.2 \%(n=72)$ agreed that PCC was a high priority in their workload while $84.8 \%$
( $n=117)$ agreed that they preferred to deal with risk factors before pregnancy rather than in pregnancy and $82.6 \%$ $(n=114)$ agreed that with PCC they could do something extra for their patients.

The attitude level had 12 items, thus the possible minimum score was 12 and the maximum score was 60 . The minimum score for the respondents was 28 and the maximum score was 55 with $M=42.9$ and s.d. $=5.17$. On grouping of the scores, with a score of less than 35 indicating unfavourable attitude and 36-60 indicating favourable attitude, the majority of respondents $92.8 \%(n=128)$ has a favourable attitude, and $7.2 \%(n=10)$ has a less favourable attitude towards PCC. Hence, on an average, the result indicates that the participant has a favourable attitude towards PCC.

\section{Difference and association of demographic with knowledge and attitude}

Non-parametric testing Kruskal Wallis and Mann-Whitney $\mathrm{U}$ were used for difference and associations between the demographic variables with knowledge and attitude. 
The Kruskal Wallis test revealed a statistically significant difference between the age of the nurses and their knowledge of PCC, $p=0.004$. There was also a statistical difference found between employment area and attitude, $p=0.005$. However, no difference was found between knowledge of PCC, attitude and other demographic variables. Mann-Whitney U tests revealed a statistically significant association between knowledge and attitude, with a $p$-value of 0.000 .

\section{Discussion}

The ultimate aim of PCC is short- and long-term improvements in maternal and child health outcomes. ${ }^{1,18}$ The results of this study found that a great percentage of the respondents (88.4\%) agreed that PCC could lead to better pregnancy outcomes. This is also consistent with a PCC study among midwives ${ }^{30}$ where the majority of them agreed that it can lead to better pregnancy outcomes. Preconception care should be provided to all reproductive-aged women irrespective of their risk profile, but those with a high-risk profile should not be neglected..$^{34}$ Therefore, the majority $(81.2 \%)$ of the study respondents had disagreed that PCC should only be offered to women with high risks. Likewise, the study among midwives ${ }^{30}$ reported that more than $80 \%$ of them disagreed that PCC should only be offered to women with high risks. The results of this study showed that $92 \%$ of the respondents agreed that PCC could reduce the incidences of unplanned and unwanted pregnancy. This echoed the findings of a systematic review and a study among women living with $\mathrm{HIV}^{35,36}$ were PCC were showed to reduce the incidences of unplanned pregnancy.

There are conflicting reports about nurses and primary health care workers' knowledge of preconception care. Several studies have revealed a low level of knowledge regarding PCC services, ${ }^{21,23,37,38}$ while a study in the United States ${ }^{39}$ reported that health care workers had a high knowledge regarding specific PCC interventions. However, the results of the present study portrayed that most respondents (55\%) were knowledgeable about PCC. These results are almost similar to the previous study on PCC by Sattarzadeh, Farshbaf-Khalili ${ }^{40}$ with a mean score of 73.21 and \pm 11.83 . Factors such as availability of PCC resources, working in public hospital, use of smartphone and practice of PCC have been cited to predict the knowledge of PCC. ${ }^{41}$ Whereas in this study, study centre, age and employment area are predictors of knowledge.

Kachoria and Shawe $\mathrm{e}^{34,42}$ observed that in many countries, preconception guidance was usually contained within the pregnancy guidelines. Not surprisingly, $44.9 \%$ had been uncertain, and $39.2 \%$ had disagreed that there is no PCC policy in South Africa. This is because currently South Africa does not have a PCC policy but has some guidance in its maternity guidelines. ${ }^{43}$ Testing and the management of HIV, especially for the prevention of vertical and horizontal transmission, are components of PCC services. ${ }^{1,44}$ Similarly, most respondents $(84.1 \%)$ also agreed that PCC could reduce the incidence of HIV PCR positive, and a further two-thirds
(71.8\%) agreed that PCC could reduce the chances of acquiring HIV among serodiscordant couples. This is consistent with the observations in the US and South Africa among people living with $\mathrm{HIV}^{44,45}$ It is also consistent with the recommendations about the goal of PCC in serodiscordant relationships. ${ }^{8}$ Interestingly, the findings of this research show that more than a quarter of the respondents $42.8 \%$ had agreed, that there was little evidence base for PCC. This is contrary to the reports of Goodfellow, ${ }^{46}$ who observed that there is a wide range of available PCC interventions with evidence of effectiveness, although some are with a more stronger evidence base than others. Although knowledge among healthcare worker on implementations and protocols about PCC interventions has been reported to be low, ${ }^{22,23}$ their general knowledge about advice and screenings required during preconception services were not. ${ }^{39}$

The results of their attitude dimensions revealed that most respondents had favourable attitude towards preconception care. These results were in line with previous literature on PCC $^{30,47}$ where health workers also possess favourable attitude. Other studies also reported positive attitude towards PCC, both among health care workers and women ${ }^{48,49}$ where $98 \%$ believed in the health benefits of PCC on pregnancy outcomes.

There is a recommendation for the establishment of a special PCC clinic. ${ }^{50}$ A dedicated PCC clinic was established in the Netherlands, Hungary and the United Kingdom ${ }^{51}$ for the provision of PCC, but this is not a norm in Africa as some African countries like South Africa have opted for the integration of PCC services into already existing care. ${ }^{43}$ Interestingly, in the present study, most respondents (45.7\%) disagreed that a dedicated clinic for PCC was a luxury service for women. Preconception care services can be rendered in a variety of settings. In the hospital settings, it has been recommended to be in the form of an opportunistic offer to every reproductive-aged woman encountered by health care providers. Nevertheless, the primary health care setting has been suggested to be the most suitable setting for these services. ${ }^{50,52}$ Similarly, almost half of the respondents (49.2\%) had disagreed that the hospital setting was the best place to provide PCC. Globally, pregnancy planning hardly happens among the general population (World Health Organization); ${ }^{20}$ likewise, the unintended pregnancy rate in sub-Saharan Africa is higher than in the developed countries. ${ }^{53}$ Not surprisingly, in the present study, $47.1 \%$ had agreed that in their practice, population planning for pregnancy did not always happen.

Time has been cited in many studies as a major barrier to the provision of preconception services. ${ }^{23,38,54}$ It is noteworthy and surprising that about $58.7 \%$ of the respondents in the present study had disagreed that there was not enough time for the provision of PCC. Even though $71.7 \%$ of the present study respondents indicated that they had never received any form of training on PCC, yet $47.8 \%$ had disagreed that as a PHC nurse they did not have enough skills to offer PCC. Furthermore, a greater percentage (82.6\%) had also disagreed 
that PHC nurses were not the best people to offer PCC. Studies have shown some degree of confusion about whose role it is to provide PCC and the need for PCC training for healthcare workers. ${ }^{8,21,30,55}$ In this study, $57.3 \%$ had disagreed that PCC without women asking for it, was unpleasant. This contrasted the study among health care providers in the United States, ${ }^{23}$ where it was revealed that providers shied away from talking about pregnancy desires with patients, except if patient initiated it themselves. Although in agreement with a study in the Netherlands, ${ }^{30}$ where a big percentage of respondents saw, raising of the topic about patients' pregnancy wishes not a barrier to PCC.

\section{Strengths and limitations}

The major limitation of the present study is that the data was collected using only the questionnaire, which may have limited the responses given by the respondents and may have been subjected to personal bias and the respondents' capacity in interpreting the questions.

Another limitation is that the study was conducted in a higher education institution using only primary health care nurses who are students, which may not be generalised to the entire PHC nurses in the district.

\section{Implications}

- There is a need to explore the patient's knowledge and attitude of preconception care, especially in the context of HIV and AIDS.

- There is the need to explore the concept using the qualitative research method for in-depth understanding of the subject.

- Further studies can explore all the primary health care workers or all the health workers that are responsible for the provision of PCC.

\section{Conclusion}

The results revealed that PHC nurses were knowledgeable about PCC, and they possess favourable attitudes towards PCC as well.

Knowledge and attitude were affected by the demographic characteristics. The knowledge of PCC was found to be influenced by study centre, employment area, and age. The high knowledge level among nurses in the rural area and those employed in the public clinics might be an indication of their job responsibility as majority of them initiate and manage patients on antiretroviral therapy. There is lack of PCC resources in the country. The provisions of PCC is very necessary for the improvement of pregnancy outcome; therefore, $\mathrm{PHC}$ nurses need to be prepared for this purpose.

\section{Acknowledgements}

The authors would like to appreciate all those who participated in the study and the managers and facilitators of the institution where the study was undertaken.

\section{Competing interests}

The authors declare that they have no financial or personal relationships that may have inappropriately influenced them in writing this article.

\section{Authors' contributions}

W.C.U. conducted the research project for her master's degree in Nursing (maternal and child health), while M.D. was the project supervisor. The article was produced from the thesis, and both authors contributed towards the compilation of this article.

\section{Funding information}

This research received no specific grant from any funding agency in the public, commercial or not-for-profit sectors.

\section{Data availability statement}

Data sharing is not applicable to this article as no new data were created or analysed in this study.

\section{Disclaimer}

This article as a professional research represents the opinion of the authors and respondents and, therefore, not the official position of the institution.

\section{References}

1. World Health Organization. Meeting to develop a global consensus on preconception care to reduce maternal and childhood mortality and morbidity. Geneva: WHO; 2013

2. Lassi ZS, Dean SV, Mallick D, Bhutta ZA. Preconception care: Delivery strategies and packages for care. Reprod Health. 2014;11(3):1-17. https://doi.org/10.1186/1742 4755-11-S1-S1

3. UNICEF. Levels and trends in child mortality. New York: UNICEF; 2011.

4. NCCEMD. Saving mothers: Annual report and detailed analysis of maternal deaths due to non-pregnancy related infections. In: National Committee for Confidentia Enquiry into Maternal Deaths RoSA, editor. Pretoria: Government Printer; 2014.

5. World Health Organization. Draft action plan for the prevention and control of noncommunicable diseases 2013-2020. Geneva: WHO; 2013.

6. Osborn D, Cutter A, Ullah F, editors. Universal sustainable development goals. Stakeholder Forum, commissioned by the UN Development Program [homepage on the Internet]. Geneva, Switzerland; 2015 [cited 2017 Apr 4]. Available from: https://sustainabledevelopment.un.org/content/documents/1684SF_-_SDG_ Universality_Report_-_May_2015.pdf.

7. You D, Hug L, Ejdemyr S, Beise J. Levels and trends in child mortality. Report 2015 Estimates developed by the UN Inter-agency Group for Child Mortality Estimation [homepage on the Internet]. UNICEF; 2015 [cited 2017 Apr 4]. Available from: https://www.who.int/maternal_child_adolescent/documents/levels_trends https://www.who.int/mater

8. Zühlke L, Acquah L. Pre-conception counselling for key cardiovascular condition in Africa: Optimising pregnancy outcomes. Cardiovas J Afr. 2016:27(2):79-83. https://doi.org/10.5830/CVJA-2016-017

9. World Health Organization. Born too soon: The global action report on preterm birth. Geneva, Switzerland: WHO; 2012.

10. Dean SV, Imam AM, Lassi ZS, Bhutta ZA. Importance of intervening in the preconception period to impact pregnancy outcomes. Nestlé Nutr Inst Workshop Ser. 2013;74:63-73. https://doi.org/10.1159/000348402

11. Eslami M, Yazdanpanah M, Taheripanah R, Andalib P, Rahimi A, Nakhaee N Importance of pre-pregnancy counseling in Iran: Results from the high risk pregnancy survey 2012. Int J Health Pol Manag. 2013;1(3):213-218. https://doi. org/10.15171/ijhpm.2013.39

12. Nielsen LA, Nielsen TRH, Holm J-C. The impact of familial predisposition to obesity and cardiovascular disease on childhood obesity. Obes Facts. 2015;8(5):319-328. https://doi.org/10.1159/000441375

13. Dean SV, Imam AM, Lassi ZS, Zulfiqar A. Systematic review of preconception risks and interventions [homepage on the Internet]. 2013 [cited 2017 Nov 17]. Available from: https://globalmotherchildresearch.tghn.org/site_media/media/articles/ Preconception_Report.pdf. 
14. Boelig RC, Coleman JS, Keller J, Sewell C, Anderson J. Preconception counseling and care in the setting of HIV: Clinical characteristics and comorbidities. Infect Dis Obstet Gynecol. 2015;2015:1-6. https://doi.org/10.1155/2015/240613

15. World Health Organization. Pre-conception care: Maximizing the gains for maternal and child health 2013 [cited 2017 Apr 21]. Available from: http://www. who.int/maternal_child_adolescent/documents/preconception_care_policy brief.pdf.

16. UNAIDS. Unaids strategy 2016-2021: On the fast track to end aids. Geneva, Switzerland: UNAIDS; 2015.

17. Upadhya KK, Jalazo ER, Connor KA, Mistry KB, Cheng TL. Optimizing preconception health among young women: What are we missing? PEDADO J Pediatr Adoles Gynecol. 2016;29(5):464-466. https://doi.org/10.1016/j.jpag.2016.02.010

18. Dean SV, Lassi ZS, Imam AM, Bhutta ZA. Preconception care: Closing the gap in the continuum of care to accelerate improvements in maternal, newborn and child health. Reprod Health. 2014;11:1-8. https://doi.org/10.1186/1742-4755 11-S3-S1

19. Mason E, Chandra-Mouli V, Baltag V, Christiansen C, Lassi ZS, Bhutta ZA Preconception care: Advancing from 'important to do and can be done' to 'is being done and is making a difference'. Reprod Health. 2014;11(3):S8. https://doi. org/10.1186/1742-4755-11-S3-S8

20. World Health Organization. Preconception care: Regional expert group consultation. New Delhi, India: WHO; 2014

21. Bortolus R, Oprandi NC, Morassutti FR, et al. Why women do not ask for information on preconception health? A qualitative study. BMC Preg Childbirth. 2017;17(1):1-11. https://doi.org/10.1186/s12884-016-1198-z

22. Ferreira FR, Akiba HRR, Júnior EA, Figueiredo EN, Abrahão AR. Prevention of birth defects in the pre-conception period: Knowledge and practice of health care professionals (nurses and doctors) in a city of Southern Brazil. Iran J Reprod Med. 2015;13(10):655-662.

23. Coll AS, Potter JE, Chakhtoura N, Alcaide ML, Cook R, Jones DL. Providers' perspectives on preconception counseling and safer conception for HIV-infected women. AIDS Care. 2016;28(4):513-518. https://doi.org/10.1080/09540121.201 5.1112349

24. Hampanda K. Vertical transmission of HIV in Sub-Saharan Africa: Applying theoretical frameworks to understand social barriers to PMTCT. ISRN Infect Dis. 2012;2013:1-5. https://doi.org/10.5402/2013/420361

25. Dinh T-H, Delaney KP, Goga A, et al. Impact of maternal HIV seroconversion during pregnancy on early mother to child transmission of HIV (MTCT) measured at 4-8 weeks postpartum in South Africa 2011-2012: A national population-based 4-8 weeks postpartum in South Africa 2011-2012: A national population-based
evaluation. PLoS One. 2015;10(5):1-17. https://doi.org/10.1371/journal.pone. 0125525

26. Kendall C, Dorward J, Mfeka G, Gate K, Claessens L. Reasons for failure of prevention of mother-to-child HIV transmission in a rural South African district hospital. S Afr HIV Med. 2015;16(1):1-3. https://doi.org/10.4102/sajhivmed.v16i1.365

27. Iyun V, Brittain K, Phillips TK, et al. Prevalence and determinants of unplanned pregnancy in HIV-positive and HIV-negative pregnant women in Cape Town South Africa: A cross-sectional study. BMJ Open. 2018;8(4):e019979. https:// douth Africa: A cross-sectional study. B

28. Collins LA. Knowledge, attitudes, and beliefs about preconception care among American adolescent females [doctoral dissertation]. Walden University; 2016.

29. Heyes T, Long S, Mathers N. Preconception care practice and beliefs of primary care workers. Fam Pract. 2004;21(1):22-27. https://doi.org/10.1093/fampra/cmh106

30. Van Voorst S, Plasschaert S, De Jong-Potjer L, Steegers E, Denktaş S. Curren practice of preconception care by primary caregivers in the Netherlands. Eur Contracep Reprod Health Care. 2016;21(3):251-218. https://doi.org/10.3109/13 625187.2016.1154524

31. Gezahegn A. Assessment knowledge and experience of preconception care among pregnant mothers attending antenatal care in West Shoa Zone Public Health Centers, 2016 [doctoral dissertation]. Addis Ababa University; 2016.

32. Polit DF, Beck $C T$. Nursing research: Generating and assessing evidence for nursing practice. Philadelphia: Lippincott Williams \& Wilkins; 2016.

33. Israel GD. Sampling the evidence of extension program impact. Gainesville, FL: University of Florida Cooperative Extension Service, Institute of Food and Agriculture Sciences: EDIS; 1992.

34. Kachoria R, Oza-Frank R. Receipt of preconception care among women with prepregnancy and gestational diabetes. Diabet Med. 2014;31(12):1690-1695. https://doi.org/10.1111/dme.12546
35. Rahangdale L, Stewart A, Stewart RD, et al. Pregnancy intentions among women living with HIV in the United States. J Acquir Immune Defic Syndr. 2014:65(3): 306-311. https://doi.org/10.1097/QAl.0000000000000014

36. Dean SV, Lassi ZS, Imam AM, Bhutta ZA. Preconception care: Promoting reproductive planning. Reprod Health. 2014;11(3):1-17. https://doi.org/10.1186/ 1742-4755-11-S3-S1

37. Braspenningx $S$, Haagdorens $M$, Blaumeiser $B$, Jacquemyn $Y$, Mortier $G$ Preconceptional care: A systematic review of the current situation and recommendations for the future. Facts Views Vis ObGyn. 2013;5(1):13-25.

38. Ojukwu O, Patel D, Stephenson J, Howden B, Shawe J. General practitioners' knowledge, attitudes and views of providing preconception care: A qualitative investigation. Upsala J Med Sci. 2016;121(4):256-263. https://doi.org/10.1080/0 3009734.2016.1215853

39. Williams JL, Abelman SM, Fassett EM, et al. Health care provider knowledge and practices regarding folic acid, United States, 2002-2003. Maternal Child Health J. 2006;10(1):67-72. https://doi.org/10.1007/s10995-006-0088-9

40. Sattarzadeh N, Farshbaf-Khalili A, Khari E. Socio-demographic predictors of midwives' knowledge and practice regarding preconception care. Int J Women Health Reprod Sci. 2017;5(3):212-217. https://doi.org/10.15296/ijwhr.2017.38

41. Kassa A, Human SP, Gemeda H. Knowledge of preconception care among healthcare providers working in public health institutions in Hawassa, Ethiopia. PLoS One. 2018;13(10):e0204415. https://doi.org/10.1371/journal.pone.0204415

42. Shawe J, Delbaere I, Ekstrand M, et al. Preconception care policy, guidelines, recommendations and services across six European countries: Belgium (Flanders), Denmark, Italy, the Netherlands, Sweden and the United Kingdom. Eur J Contracept Reprod Health Care. 2015;20(2):77-87.

43. NDoH. Guidelines for maternity care in South Africa: A manual for clinics, community health centres and district hospitals. In: National Department of Health RoSA, editor. 4th ed. Pretoria: Government Printer; 2015.

44. Hoyt MJ, Storm DS, Aaron E, Anderson J. Preconception and contraceptive care for women living with HIV. Infect Dis Obstet Gynecol. 2012;2012:1-14. https://doi. org/10.1155/2012/604183

45. Moodley T, Moodley D, Sebitloane M, Maharaj N, Sartorius B. Improved pregnancy outcomes with increasing antiretroviral coverage in South Africa. BMC Pregnancy Childbirth. 2016;16(35):1-10. https://doi.org/10.1186/s12884-016-0821-3

46. Goodfellow A. Improving preconception care in Lanarkshire [homepage on the Internet]. 2015 [cited 2017 Nov 10]. Available from: http://www.nhslanarkshire.org. uk/publications/Documents/Improving-Preconception-Care-in-NHS-Lanarkshire.pdf.

47. Klein J, Boyle J, Kirkham R, et al. Preconception care for women with type 2 diabetes mellitus: A mixed-methods study of provider knowledge and practice. Diabetes Res Clin Pract. 2017;129:105-115. https://doi.org/10.1016/j.diabres.2017.03.035

48. Ahmed K, Elbashir IMH, Ibrahim SM, Mohamed AKM, Alawad AAM. Knowledge, attitude and practice of preconception care among Sudanese women in reproductive pge about rheumatic heart disease at Alshab and Ahmad Gassim hospitals 2014-2015 in Sudan. Basic Res J Med Clin Sci. 2015;4(7):199-203.

49. Posner SF, Johnson K, Parker C, Atrash H, Biermann J. The national summit on preconception care: A summary of concepts and recommendations. Materna Child Health J. 2006;10:199-207. https://doi.org/10.1007/s10995-006-0107-x

50. Poels M, Koster MPH, Franx A, Van Stel HF. Healthcare providers' views on the delivery of preconception care in a local community setting in the Netherlands. BMC Health Serv Res. 2017;17(1):92. https://doi.org/10.1186/s12913-017-2051-4

51. Boulet SL, Parker C, Atrash H. Preconception care in international settings. Maternal Child Health J. 2006;10(1):29-35. https://doi.org/10.1007/s10995-0060091-1

52. Shannon GD, Alberg C, Nacul L, Pashayan N. Preconception healthcare delivery at a population level: Construction of public health models of preconception care Matern Child Health J. 2014;18(6):1512-1531. https://doi.org/10.1007/s10995 013-1393-8

53. Singh S, Sedgh G, Hussain R. Unintended pregnancy: Worldwide levels, trends, and outcomes. Stud Fam Plan. 2010;41(4):241-250. https://doi.org/10.1111/j.1728 4465.2010.00250.x

54. Mazza D, Chapman A, Michie S. Barriers to the implementation of preconception care guidelines as perceived by general practitioners: A qualitative study. BMC Health Serv Res. 2013;13(1):1-8. https://doi.org/10.1186/1472-6963-13-36

55. Stephenson J, Patel D, Barrett G, et al. How do women prepare for pregnancy? Preconception experiences of women attending antenatal services and views of health professionals. PLoS One. 2014;9(7):1-11. https://doi.org/10.1371/journal. pone.0103085 